\title{
Article
}

Arq Neuropsiquiatr 2010;68(2):212-215

\section{Botulinum neurotoxin type-A for primary stabbing headache

\author{
An open study
}

\author{
Elcio Juliato Piovesan, Helio Ghizoni Teive, Pedro André Kowacs, \\ Lucas Leite da Silva, Lineu Cesar Werneck
}

\begin{abstract}
Primary stabbing headache is an ultra-short headache, associated with primary headaches, more prevalent in women and with a poor response to therapy. The effect of botulinum neurotoxin type-A (BoNTA) on primary stabbing headache was investigated in 24 patients. Three patients showed complete remission. Nineteen patients showed a decrease in their primary stabbing headaches that started in the second week, and that was sustained during approximately 63 days. In two patients BoNTA showed no therapeutic effect. The BoNTA seems to be an excellent therapeutic option for primary stabbing headache.
\end{abstract}

Key words: botulinum neurotoxin type $A$, headache treatment, primary stabbing headache.

Toxina botulínica do tipo-A para o tratamento da cefaléia primária em punhaladas: um estudo aberto

\section{RESUMO \\ Cefaléia primária em punhaladas (CPP) é uma cefaléia ultra-rápida, associada a cefaléias primárias, mais frequente em mulheres e com discreta resposta terapêutica. $O$ efeito da neurotoxina botulínica do tipo A (NTBo-A) sobre a CPP foi investigado em 24 pacientes. Três pacientes apresentaram completa remissão dos sintomas. Dezenove pacientes mostraram uma redução que começou na segunda semana e que manteve-se por um período de 63 dias. Em dois pacientes a NTBo-A não apresentou nenhum efeito terapêutico. A NTBo-A parece ser uma excelente opção terapêutica no tratamento da CPP. \\ Palavras-chave: cefaléia primária em punhaladas, tratamento, toxina botulínica do tipo-A.}

\section{Correspondence}

Elcio Juliato Piovesan

Rua General Carneiro 181

80060-900 Curitiba PR - Brasil

E-mail: piovesan@avalon.sul.com.br

piovesan1@hotmail.com

Received 12 August 2009

Received in final form 23 November 2009

Accepted 3 December 2009
Primary stabbing headache (PSH) was first described in 1964 by Lansche ${ }^{1}$ as "ophthalmodynia periodica" and over the years it has been known by many synonyms, e.g. "idiopathic stabbing headache", ice-pick headache syndrome ${ }^{2}$ and jabs and jolts ${ }^{3}$. Recently it has been included as a separate entity in the classification of the International Headache Society (IHS) under the umbrella of "other primary headaches".

PSH is a paroxysmal disorder manifested by transient painful stabs. Epidemiological studies demonstrated that it occurs $2 \%$ to $32.5 \%$ of an adult healthy population ${ }^{5,6}$. Previous reports have identified PSH in both normal and headache-prone adults, mainly those affected by tension-type headache or migraine. The pathophysiology of PSH remains largely unknown, what makes therapeutic approaches to be empirical and challenging. Indomethacin has been traditionally seen as the first-line option, but failure occurs up to $35 \%$ of cases so that novel treatment possibilities are clearly needed ${ }^{7}$.

We report a case series in which botulinum neurotoxin type A (BoNT-A) was used as therapeutic option for the treatment of PSH. The characteristics of PSH in this particular group are also described. 


\section{METHOD}

Twenty six patients who met the IHS criteria for PSH were included in the study. The patients were instructed to record the frequency and other clinical characteristics of PSH stabs during a seven-day "run-in" period. Two patients dropped out due to failure to gather reliable information during this phase. Twenty-four patients concluded the study. The average age was $43.02 \pm 17.91$ years. The female patients $(n=20)$ were $42.5 \pm 18.91$ years-old and the four male patients $45.75 \pm 13.5$ years-old. Age did not differ significantly from both groups $(\mathrm{p}=0.561)$. All patients had prior treatment with indomethacin without clinical response.

After the run-in period, the patients were submitted to BoNT-A five unit per PSH stabbing zone. Stabbing zone was considered as the point where it causes the painful symptoms, as the definition of this pathology PSH is a pain point type, stab, we believe that this region it is similar the area of digital pulp of the examiner finger. We realized only one blockaded over this zone. The patients that non-localized stabs were excluded. Patients with multiple zones were treatment only one and both zones in the same time The frequency of the patient's jabs was surveyed weekly after the injection of BoNT-A until the $70^{\text {th }}$ day. Reduction of PSH jabs was the primary end point measurement.

For the injection we utilized syringe/needle insulin brand ultra BD 30G, with a length of $8 \mathrm{~mm} \mathrm{(5/16")} \mathrm{and} \mathrm{a}$ size of $0.3 \mathrm{~mm}$. The NTBo-A was used Botox ${ }^{\circ}$ (Allergan, Inc. Irvine, CA - USA) with subcutaneous inoculation. Bottles of NTBo-A containing 100 units were reconstructed using a saline solution $0.9 \%-2 \mathrm{ml}$ (50U/mouse per $\mathrm{ml}$ ).

The study was approved by the local Institutional Regulatory Board and all patients signed an informed consent for this publication. The data presented as mean \pm SD. The frequency of the stabs at different time points a parametric (Student's t-test) was used. Comparison between genders was done with a non-parametric test (Mann-Whitney's test). Statistical significance was fixed at $\mathrm{p}<0.05$.

\section{RESULTS}

\section{Time, duration and distribution of the jabs}

Mean time since the start of the jabs was $2.95 \pm 2.68$ years. The mean duration of the jabs was described as $1.35 \pm 0.81$ seconds. No differences in the duration of the jabs were observed between female and males $(\mathrm{p}=0.662)$. A side-locked distribution was observed in 21 patients (87.5\%) and bilateral in other three patients (12.5\%). Distribution of the scalp were the following: temporal regions in 16 patients (53.3\%); occipital region in eight patients (26.7\%); parietal region four patients (13.3\%); ocular region one patient (3.3\%) and frontal region one patient (3.3\%) (Fig 1).

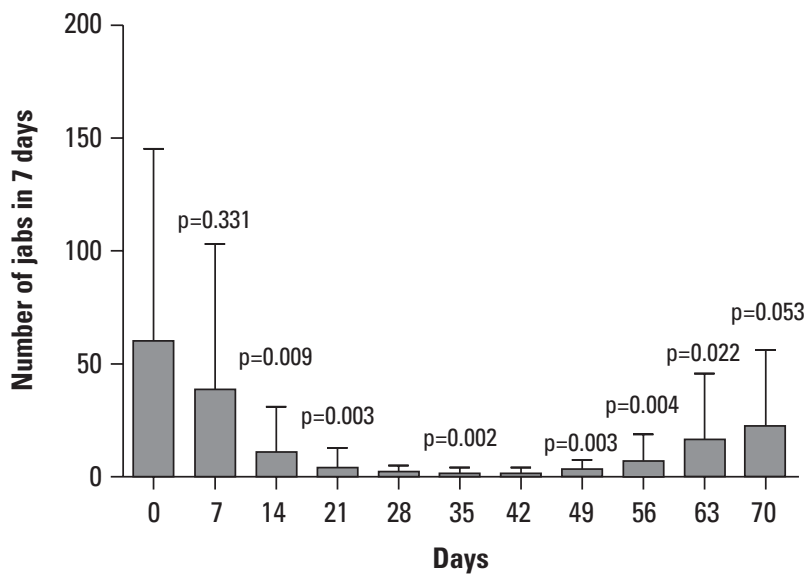

Fig 1. Jabs frequency distribution during the study.

\section{Triggering factors, pattern and intensity}

Twenty patients did not report triggering factors. Four patients reported the jabs to have started after a clinical event, to know: cranial trauma (two patients, $8.3 \%$ ) and stroke (two patients, 8.3\%). However the jabs have not relationship with the vascular territory of the stroke and had no relation with the region of cranial trauma, because this we included these cases also with PSH. The exploding pattern (perceived a painful buildup of pressure inside the head, i.e., inside to outside direction ) was found in 23 patients (95.8\%) and imploding pattern (perceived a painful assault on the outside of the head, i.e., outside to inside direction) in one patient (4.2\%). Mean intensity of the jabs were of $8.48 \pm 0.62$ points in the visual analogue scale (VAS). No differences between female and male groups were found $(\mathrm{p}=0.426)$.

\section{Vocalization, different pains and associated symptoms}

Fourteen patients reported jabs (58.3\%) and jolts were described by twelve patients (50\%). After the jabs, no residual pain was reported by eleven patients (45.8\%). Thirteen patients reported other pain symptoms (54.2\%). These symptoms were: burning sensation, eight patients (33.3\%); stabbing pain, one patient (4.2\%); pressure sensation, four patients (16.7\%). The post-jabs pain symptoms were reported to last $16.08 \pm 14.31$ minutes. Allodynia was reported to occur by three patients (all female) (12.5\%) and lasted $70.33 \pm 96.07$ minutes, with a median of 30 minutes.

Eighteen patients reported no associated symptoms (66.7\%). Associated dizziness, red eyes and blurred vision and tearing were reported by two patients each (7.4\%). A single patient reported concomitant myoclonic seizures (3.7\%).

\section{Other associated primary headaches}

Fourteen patients reported other associated headache (62.6\%). Migraine without aura was reported by nine pa- 

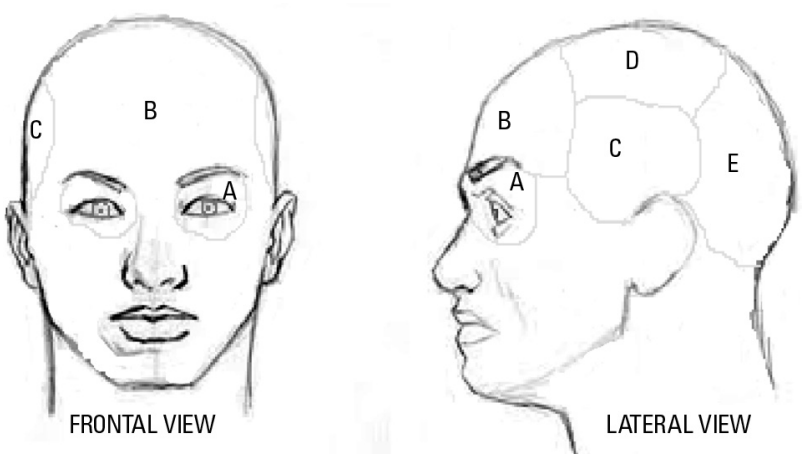

\begin{tabular}{ccc}
\hline Place & $\mathbf{n}$ & $\%$ \\
\hline Orbital & 1 & 3.3 \\
Frontal & 1 & 3.3 \\
Temporal & 16 & 53.3 \\
Parietal & 4 & 13.3 \\
Occipital & 8 & 26.7 \\
Total & 30 & 100 \\
\hline
\end{tabular}

Fig 2. Distribution of the Jabs.

tients (37.5\%) and Migraine aura without headache in one of them. Tension-type headaches were reported by six patients (25.1\%) to know: four patients with chronic tension-type headache with pericranial stiffness (16.7\%); one patient with infrequently and one with frequently episodic tension-type headache without pericranial stiffness (4.2\%).

\section{BoNT-A dose and effect}

The mean dose of BoNT-A was 11.81 7.17 units. Two patients reported no therapeutic effect of BoNT-A (8.3\%), twenty-two patients showed control of the stabs with BoNT-A (91.7\%). The BoNT-A antinociceptive effect started after seven days and was sustained for a mean of 63 days (Table and Fig 2).

\section{Side effects and special conditions}

No patients reported side-effects. The only patient that reported jabs over an eye was submitted to an anesthetic block of the supra-orbital nerve.

\section{DISCUSSION}

Primary stabbing headache showed excellent response with BoNT-A treatment (91.7\%) without side effects. In our observation PSH is an ultra-short headache with trigeminal predominantly with associated post-jabs pain symptoms.

\section{Nosological considerations}

According to the International Headache Society the PSH is: (1) Confined to the head, exclusively or predominantly felt in the distribution of the first division of the trigeminal nerve (orbital, temporal and parietal regions). In our cases, eight patients reported jabs over the occipital regions. (2) The pain is stabbing in nature and lasting fractions of a second (our cases the lasting was $1.35 \pm 0.81$ seconds); (3) Recurring at irregular intervals (hours to days); (4) Occurring in the absence of organic disease (four cases were relationship with stroke and cranial trau$\mathrm{ma})$. These four patients were kept in the study, as a primary forms, because they had no anatomical relationship between the etiology and clinical manifestations.

\section{Epidemiological considerations}

Available information on PSH shows a clear female preponderance, such as seen in our series (5 female: 1 male $)^{8}$. Association with migraine has been reported as within the $40 \%$ bracket $^{8}$, a rate akin to that seen in our sample (40.4\%). In our series, the frequency or tension type headache may have fallen within that seen in the general population. There are no reports of association between PSH and the trigemino-autonomic cephalalgias, and none was found in our series.

Table. Frequency of jab attacks per week throughout the study.

\begin{tabular}{ccccccc}
\hline \multicolumn{2}{c}{ Group - Days } & $\mathrm{n}$ & Mean $\pm \mathrm{sd}$ & Median & Correlation groups & $\mathrm{p}$ \\
\hline$(1)$ & Run-in & 24 & $60.04 \pm 85.22$ & 21 & 1 & - \\
$(2)$ & 7 & 24 & $38.58 \pm 64.57$ & 14.5 & 1 versus 2 & 0.331 \\
$(3)$ & 14 & 24 & $10.87 \pm 20.28$ & 5 & 1 versus 3 & $0.009^{*}$ \\
$(4)$ & 21 & 24 & $4.33 \pm 8.63$ & 2 & 1 versus 4 & $0.003^{*}$ \\
$(5)$ & 28 & 24 & $2.20 \pm 2.90$ & 1.5 & 1 versus 5 & $0.002^{*}$ \\
$(6)$ & 35 & 24 & $1.50 \pm 2.70$ & 0 & 1 versus 6 & $0.002^{*}$ \\
$(7)$ & 42 & 24 & $1.54 \pm 2.68$ & 0 & 1 versus 7 & $0.002^{*}$ \\
$(8)$ & 49 & 24 & $3.41 \pm 4.17$ & 1.5 & 1 versus 8 & $0.003^{*}$ \\
$(9)$ & 56 & 24 & $7.25 \pm 11.62$ & 5 & 1 versus 9 & $0.004^{*}$ \\
$(10)$ & 63 & 24 & $16.41 \pm 29.33$ & 8 & 1 versus 10 & $0.022^{*}$ \\
$(11)$ & 70 & 24 & $22.37 \pm 33.86$ & 13 & 1 versus 11 & 0.053 \\
\hline
\end{tabular}




\section{Clinical features}

Daily episodes occur in 57\% of the cases, $14 \%$ weekly, $23 \%$ monthly and $6 \%$ yearly episodes. In our series, the frequency was daily, or almost daily, probably because this is a selected group ${ }^{7}$. The majority of the patients, the pain lasting up to three seconds ${ }^{6}$. The pain has moderate severity and may recur up to 50 times daily ${ }^{7}$. In our study, the intensity of the pain was reported to be moderate to severe (VAS $=8.48 \pm 0.62$ points). Measuring the intensity of the jabs is difficult, especially because the pain paroxysms fall in the ultra-short range. Other negative factor is that the intensity of the pain must be evaluated at the time that it occurs, and it rarely happens during the medical visit. Consequently, the pain might be under evaluated. Clinically, primary stabbing headache patients, suffer brief sharp or stabbing pains that occur either as a single episode or in brief repeated volleys of pain ${ }^{6}$. In our casuistic, we described one patient that showed 100 episodes per day.

\section{Pathophysiological considerations}

Mechanisms involved in the pathogenesis of this condition remain unclear. Current theories attribute key roles to irritation of peripheral nerve roots and transitory deficits in central inhibitory pathways for pain control ${ }^{9}$. Besides, the extremely short duration of the episodes and the stabbing quality of the pain closely resemble the pattern reported in trigeminal neuralgia and point to abnormal paroxysmal neuronal discharges. The main action of the BoNT-A in a model of trigeminal pain induced by peripheral constriction is the inhibition of peripheral sensitization (personal observation). Probably this is the effect that underlies the excellent results observed in our series.

\section{Considerations on PSH therapy}

Other therapeutic options for PSH not used in our patients include: indomethacin ${ }^{7}$; nifidipine ${ }^{10}$, cyclooxygenase-2 (COX-2) selective inhibitors ${ }^{10}$ and etoricoxib ${ }^{11}$; gabapentin ${ }^{12}$ and melatonin ${ }^{13}$.

Our case series illustrates the excellent results observed in PSH patients after BoNT-A injections. Neither one of the therapeutic options previously reported ${ }^{7,9-13}$ for PSH, showed similar results. We suggested BoNT-A to be included among the therapeutic options for focal, localized PSH.

ACKNOWLEDGMENTS - The authors express their appreciation and thanks to Ms. Marisa Avelar de Morais for reviewing the style.

\section{REFERENCES}

1. Lansche R. Ophthalmodynia periodica. Headache 1964;4:247-249.

2. Raskin NH, Schwartz RK. Ice pick-like pain. Neurology 1980;3:203-205.

3. Sjaastad O, Egge K, Horven I, et al. Chronic paroxysmal hemicranias: mechanical precipitation of attacks. Headache 1979;19:31-36.

4. International Headache Society Classification Subcommittee: International classification of headache disorders. Cephalalgia 2004;24(Suppl 1):S1-S160.

5. Rasmussen BK, Olesen J. Epidemiology of migraine and tension-type headache. Curr Opin Neurol 1994;7:264-271.

6. Sjaastad O Pettersen H, Bakketeig LS. The Vägä study, epidemiology of headache: the prevalence of ultra-short paroxysms. Cephalalgia 2001;21: 205-207.

7. Pareja JA, Ruiz J, Isla C, al-Sabbah H, Espejo J. Idiopathic stabbing headache (jabs and jolts syndrome). Cephalalgia 1996;16:93-96.

8. Piovesan EJ, Kowacs PA, Lange MC, Pacheco C, Piovesan LR, Werneck LC Prevalence and semiologica aspects of the idiopathic stabbing headache in a migraine population. Arq Neuropsiquiatr 2001;59:201-205.

9. Piovesan EJ, Zukerman E, Kowacs PA, Werneck LC. Cox-2 inhibitor for the treatment of idiopathic stabbing headache secondary to cerebrovascular diseases. Cephalalgia 2002; 22:197-200.

10. Jacome DE. Exploding head syndrome and idiopathic stabbing headache relieved by nifedipine. Cephalalgia 2001;21:617-618.

11. O'Connor MB, Murphy E, Phelan MJ, Regan MJ. The use of etoricoxib to treat an idiopathic stabbing headache: a case report. J Med Case Reports 2007;1:100.

12. França MC Jr, Costa AL, Maciel JA Jr. Gabapentin-responsive idiophatic stabbing headache. Cephalalgia 2004;24:993-996.

13. Rozen TD. Melatonin as a treatment for indomethacin responsive headaches. Neurology 2003;61:865-866. 